\title{
Sensitivity of Seed Germination to Salt Stress in Black Cumin (Nigella sativa L.)
}

\section{Panayiota PAPASTYLIANOU*, Nikolia-Nonika BAKOGIANNI, Ilias TRAVLOS, Ioannis ROUSSIS}

\author{
Agricultural University of Athens, Faculty of Crop Science, 75 Iera Odos, 11855, Athens, \\ Greece;ppapastyl@aua.gr (*correspondingauthor); stud109081@aua.gr; travlos@aua.gr;iroussis01@gmail.com
}

\begin{abstract}
Black cumin is an annual oilseed crop, native to the Mediterranean region and widely used for nutritional and medicinal purposes. Reduced seed germination and early seedling growth under saline conditions are considered as major factors limiting the establishment of crops. The objective of this study was to investigate the effect of salinity due to $\mathrm{NaCl}$ on germination of black cumin seeds. A set of experiments was conducted under completely randomized design with four replications of 200 seeds at two different suboptimal germination temperatures $\left(15\right.$ and $\left.20^{\circ} \mathrm{C}\right)$ in the dark for 16 days. In order to create salt stress conditions during the germination process, five solutions were used ( 0 as control, $80,160,240$ and $320 \mathrm{mM} \mathrm{NaCl})$. The germination performance was evaluated by final germination percentage and mean germination time. The effect of salinity on seed germination percentage and mean germination time was significant at $\mathrm{p}<0.01$. Germination of the controls was $96 \%$ and $95 \%$ at $15^{\circ} \mathrm{C}$ and $20^{\circ} \mathrm{C}$, respectively. The presence of $\mathrm{NaCl}$, regardless of temperature, reduced germination. This reduction was more severe at $15^{\circ} \mathrm{C}\left(15 \%\right.$, and $19 \%$ germination in cases of 80 and $160 \mathrm{mM}$ concentration respectively) than at $20^{\circ} \mathrm{C}$ $(65 \%$ at $80 \mathrm{mM}$ salinity level) and no germination was observed from $240 \mathrm{mM}$ onwards. The mean germination time increased with increased $\mathrm{NaCl}$ levels, especially at the lower temperature of $15^{\circ} \mathrm{C}$. The overall results of this experiment showed the inhibitory effects of salt stress on seed germination parameters of black cumin.
\end{abstract}

Keywords: Germination percentage, germination time, $\mathrm{NaCl}$, Nigella sativa, salinity, seed germination, temperature

\section{Introduction}

Black cumin (Nigella sativa L.) is an annual oilseed crop, belonging to the Ranunculaceae family, native to the Mediterranean region. The crop is cultivated throughout South Europe, Syria, Egypt, Saudi Arabia, Iran, Pakistan India and Turkey (Datta et al., 2012). Black cumin is a generally short-lived annual, typical of disturbed soils or natural communities of semiarid areas, with a dominance of therophytes (Tuncturk et al., 2012). It is widely used for nutritional and medicinal purposes in many countries because of its high oil, antioxidant and protein contents (Ramadan, 2007). The seeds or their extracts contain antiabetic, antihistaminic, anti-hypertensive, antiinflammatory, antimicrobial, antitumor, galactagogue and insect repellent effects. Most properties are mainly attributed to quinone constituents, of which thymoquinone is the most abundant compound, as high as $25 \%$ in the seed oil (D’ Antuono et al., 2002). Recently, black cumin seed has identified as a valuable source of edible oil with 24.8$29.2 \%$ saturated and $69.7-73.5 \%$ unsaturated fatty acids (Piras et al., 2013).

Seed germination and seedling growth are the two critical stages for the establishment of crops. Germination of high quality seeds may be delayed or prevented by various abiotic stresses (Ashraf and Foolad, 2005). Salinity is one of the major abiotic stresses that affect crop production in arid and semi-arid areas. This is owing to inappropriate management of irrigation and drainage, low precipitation, high evaporation and irrigation with saline waters (Munns and Tester, 2008). Seed germination and seedling growth are the stages most sensitive to salinity. Salt stress causes adverse physiological and biochemical changes in germinating seeds. It can affect seed germination and stand establishment through osmotic stress, ion-specific effects and oxidative stress. Higher level of salt stress inhibits the germination of seeds while lower level of salinity induces a state of dormancy (Ibrahim 2016). Indeed, seeds subjected to salinity show variations in germination, some fail to germinate, while others tolerate salinity even at high 
concentrations (Ashraf and Foolad, 2005). In the semi-arid regions of the Mediterranean Basin, water and salinity stresses are increasingly becoming primary limiting environmental conditions, which restrict successful establishment of crops. Seed germination may be significantly reduced and delayed by the decreasing rate of water absorption when saline water is used for irrigation or when soil salinity is high. Under these conditions, salt stress may also cause excessive uptake of ions (Murillo-Amador $e t$ al., 2002).

It appears that little information is available, and with contradicting results regarding the effect of salinity on germination of black cumin seeds. In particular, increasing salinity reduced the seed germination percentage of Nigella sativa and no germination occurred in the highest salinity stress (Faravani et al., 2013; Javadi et al., 2014; Ahmadian et al., 2015). However, another study reported a decrease in root length and shoot length of Nigella sativa seedlings by increasing salinity to $150 \mathrm{ml} \mathrm{mol}$ at a constant temperature of $25^{\circ} \mathrm{C}$, with a germination rate of 95 to $82 \%$ in less than a week and suggests that black cumin is a salt tolerant plant (Hajar et al., 1996).

The objective of this study was to investigate the effect of salinity due to $\mathrm{NaCl}$ on germination of black cumin seeds.

\section{Materials and Methods}

\section{Seed material}

Seeds of Nigella sativa L. were obtained from the local market. Seeds were surface sterilised in a $1 \%$ sodium hypochlorite solution, rinsed in distilled water and dried before the experiment ( $4.4 \%$ seed moisture).

\section{Germination tests}

A set of experiments was conducted under completely randomised design with four replications. Seeds were germinated at two constant temperatures $15^{\circ} \mathrm{C}$ and $20^{\circ} \mathrm{C}$, maintained in a thermostatically controlled incubator $( \pm 1$ ${ }^{\circ} \mathrm{C}$ ) for 16 days. Samples of 800 seeds (four replicates of 200 seeds each) were placed in covered 9-cm Petri dishes between two Whatman No. 1 filter papers moistened with $7 \mathrm{~mL}$ of $\mathrm{NaCl}$ solutions. Petri dishes were hermetically sealed with parafilm to prevent evaporation and then randomised in an incubator in the dark. The seeds were kept in the dishes to assess germination. This was scored when the radicle approached approximately $2 \mathrm{~mm}$ length and data were collected daily until no additional germination had occurred for $48 \mathrm{~h}$. At the end of the tests, the final percentage germination was calculated. Using the daily counts, the mean germination time (MGT) was calculated for each lot using the formula cited by Ellis and Roberts (1980) given below, MGT $=\sum \mathrm{n} . \mathrm{D} / \sum \mathrm{n}$ where $\mathrm{n}=$ number of seeds newly germinated at time $\mathrm{D} ; \mathrm{D}=$ days from the beginning of the germination test, $\Sigma \mathrm{n}=$ final germination.

\section{Salt solutions}

Five solutions were prepared, dissolving different concentration of $\mathrm{NaCl}$ in distilled water ( 0 as control, 80 , 160,240 and $320 \mathrm{mM}$ ). Salt solutions were used in germination tests to imbibe seeds.
Statistical analysis

Data of the final germination percentage (arcsine transformed) and mean germination time were statistically analyzed by a completely randomized two-way analysis of variance (ANOVA) using the StatSoft software (1999). The analysis of variance was conducted considering osmotic potential and temperatures as fixed factors. When ' $F$ ' ratios were significant, means were separated by the StudentNewman-Keuls (SNK) test at $\leq 0.05$.

\section{Results and Discussion}

The cumulative seed germination time courses during imbibition at different concentrations in $\mathrm{NaCl}$ solution are shown in Figs. 1 and 2. Final germination percentage of the controls was $96 \%$ and $95 \%$ at $15^{\circ} \mathrm{C}$ and $20^{\circ} \mathrm{C}$, respectively. Comparable results were reported by Ghaderi et al. (2008) who found that germination percentage of black cumin seeds at $10-30^{\circ} \mathrm{C}$ was between $88-96 \%$. Several authors have reported that salinity stress affects seed germination either by decreasing the rate of water uptake (osmotic effect) and/or by facilitating the intake of ions (ion toxicity), which may change enzymatic or hormonal activities inside the seed (Murillo-Amador et al., 2002; Ashraf and Foolad, 2005). In general, seeds from the controls showed a higher rate and final germination percentage and a lower mean germination time compared to seeds from the salt treatments. The effect of salinity on seed germination percentage and mean germination time was significant at $\mathrm{p}<0.01$ (Table 1 ). The presence of $\mathrm{NaCl}$, regardless of temperature, reduced germination. This reduction was more severe at $15^{\circ} \mathrm{C}(15 \%$, and $19 \%$ germination in case of 80 and $160 \mathrm{mM}$ concentration, respectively) than at $20{ }^{\circ} \mathrm{C}(65 \%$ at $80 \mathrm{mM}$ salinity level) and no germination was observed from 240 $\mathrm{mM}$ onwards (Figs. 1 and 2, Table 1). The mean germination time increased with the reduction of water potential, especially at the lower temperature of $15^{\circ} \mathrm{C}$ (Table 1). Similar effects were observed in seed germination, seedling emergence and seedling survival of Nigella sativa in the laboratory and the field (Faravani et al., 2013). Moreover, our results were in agreement with the findings of Javadi et al. (2014) and Ahmadian et al. (2015) who found that high levels of salinity can significantly inhibit seed germination in black cumin. In particular, increasing of

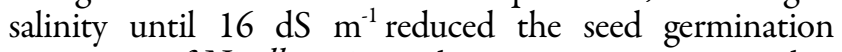
percentage of Nigella sativa and no germination occurred in

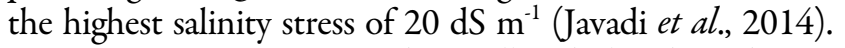
Germination percentage drastically declined and was delayed with increase of osmotic stress due to $\mathrm{NaCl}$ in $\mathrm{MPa}$ lower than -0.9 (Ahmadian et al., 2015) and in salinity stress below $21 \mathrm{dS} \mathrm{m} \mathrm{m}^{-1}$ (Faravani et al., 2013). Conversely, as reported by Hajar et al. (1996) the seeds showed a germination rate of $95 \%$ to $82 \%$ in less than a week in salinity $150 \mathrm{ml} \mathrm{mol}$ at a constant temperature of $25^{\circ} \mathrm{C}$, and suggest that black cumin is a salt tolerant plant.

Salinity sensitivity of black cumin varied in different growth stages from germination to harvest. Saline soil causes physiological and metabolic disorders in seed germination, survival percentage, morphological characteristics of plants, affecting development, growth, yield, and quality of plants (Al-Jassir, 1992; Faravani et al., 2013; Khalid 2015). 
204

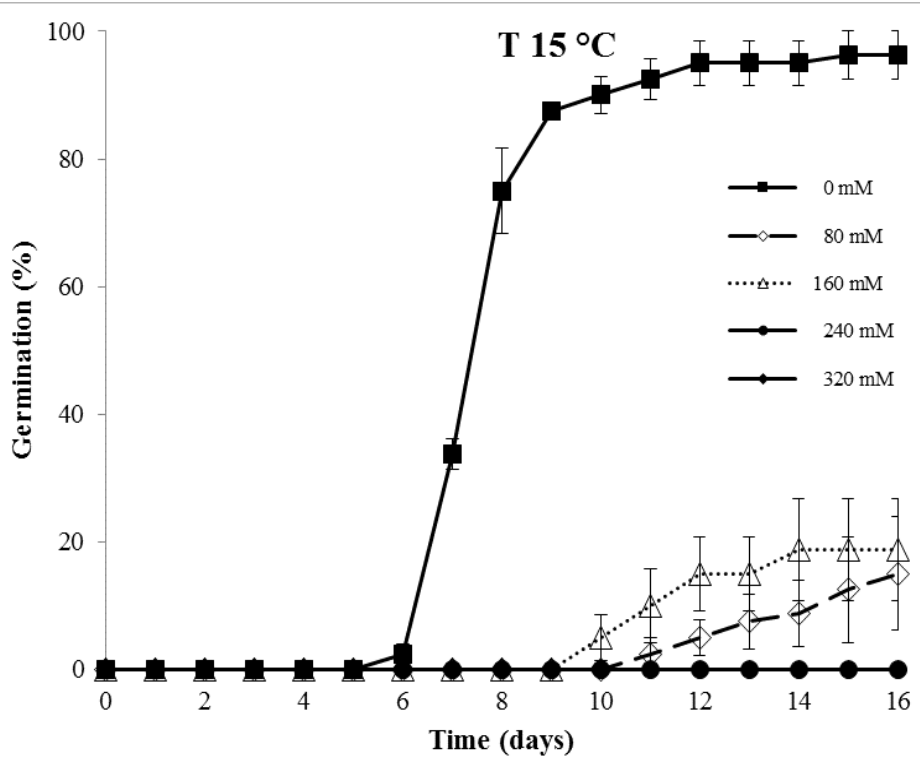

Fig. 1. Cumulative germination of black cumin seeds exposed to $\mathrm{NaCl}$ solutions at $15^{\circ} \mathrm{C}$. Vertical bars represent the standard error

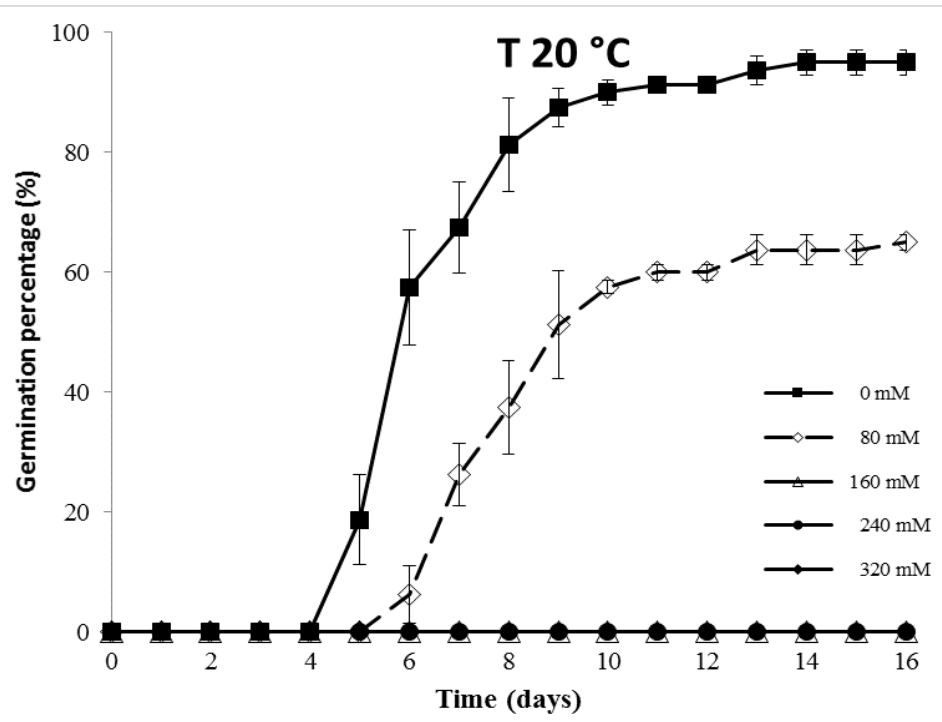

Fig. 2. Cumulative germination of black cumin seeds exposed to $\mathrm{NaCl}$ solutions at $20^{\circ} \mathrm{C}$. Vertical bars represent the standard error

Table 1. Results from an analysis of variance showing the effects of $\mathrm{NaCl}$ solutions on final germination percentage and mean germination time of black cumin seeds germinated at $15^{\circ} \mathrm{C}$ and $20^{\circ} \mathrm{C}$

\begin{tabular}{|c|c|c|c|c|c|}
\hline \multirow[b]{2}{*}{$\mathrm{C}(\mathrm{mM})$} & \multicolumn{2}{|c|}{ Germination $(\%)$} & \multicolumn{3}{|c|}{ Mean germination time (days) } \\
\hline & $15^{\circ} \mathrm{C}$ & $20^{\circ} \mathrm{C}$ & $15^{\circ} \mathrm{C}$ & & $20^{\circ} \mathrm{C}$ \\
\hline 0 & $96.3 \mathrm{a}$ & $95.0 \mathrm{a}$ & $8.06 \mathrm{a}$ & & $6.83 \mathrm{a}$ \\
\hline 80 & $15.0 \mathrm{~b}$ & $65.0 \mathrm{~b}$ & $10.3 \mathrm{~b}$ & & $8.96 \mathrm{~b}$ \\
\hline 160 & $18.8 \mathrm{~b}$ & $0 \mathrm{c}$ & $11.7 \mathrm{c}$ & & $0 \mathrm{c}$ \\
\hline 240 & $0 \mathrm{~b}$ & $0 \mathrm{c}$ & $0 \mathrm{~d}$ & & $0 \mathrm{c}$ \\
\hline 320 & $0 \mathrm{~b}$ & $0 \mathrm{c}$ & $0 \mathrm{~d}$ & & $0 \mathrm{c}$ \\
\hline Average & $26 \mathrm{~A}$ & $32 \mathrm{~A}$ & $6.02 \mathrm{~A}$ & & $3.16 \mathrm{~B}$ \\
\hline \multicolumn{6}{|l|}{ Significance } \\
\hline $\mathrm{C}$ & \multicolumn{2}{|c|}{ *** } & \multicolumn{3}{|c|}{ *** } \\
\hline $\mathrm{T}$ & \multicolumn{2}{|c|}{ ns } & \multicolumn{3}{|c|}{ *** } \\
\hline $\mathrm{C} \times \mathrm{T}$ & \multicolumn{2}{|c|}{$* * *$} & \multicolumn{3}{|c|}{ *** } \\
\hline
\end{tabular}

C, salt concentrations, T, temperatures. ns, not significant; significant at ${ }^{*} \mathrm{p}<0.05,{ }^{* *} \mathrm{p}<0.01,{ }^{* * *} \mathrm{p}<0.001$. Percentage data were transformed before analysis; actual values (means of the main factors) are shown. Values belonging to the same characteristic with different lower-case letters within a column indicate significant differences between osmotic potential mean values and different upper-case letters within a row indicate significant differences between the means of temperatures tested according to Student-Newman-Keuls test at $\mathrm{p}<0.05$ 


\section{Conclusions}

The overall results of this experiment showed the inhibitory effects of salt stress on seed germination parameters of black cumin. The lowering of the temperature from the optimal one makes the seeds more sensitive to salinity and at $15^{\circ} \mathrm{C}$, which is a temperature close to those occurring during black cumin sowing in the Mediterranean regions, seed germination declines rapidly. Other parameters beside seed germination and mean germination time, such as seedling emergence, root, shoot length and weight, may be helpful indicators in breeding programmes towards the development of salt stress-tolerant cultivars. In addition priming techniques may be useful in overcoming the negative effect imposed by salinity upon seed germination under suboptimal thermal conditions.

\section{References}

Ahmadian A, Shiri Y, Froozandeh M (2015). Study of germination and seedling growth of black cumin (Nigella sativa L.) treated by hydro and osmopriming under salt stress conditions. Cercetări Agronomice în Moldova 48(2):69-78.

Al-Jassir MS (1992): Chemical composition and microflora of black cumin (Nigella sativa L.) seeds growing in Saudi Arabia. Food Chemistry 45:239-242.

Ashraf M, Foolad MR (2005). Pre-sowing seed treatment-a shotgun approach to improve germination, plant growth, and crop yield under saline and non-saline conditions. Advances in Agronomy 88:223-271.

D'Antuono LF, Moretti A, Lovato AFS (2002). Seed yield, yield components, oil content and essential oil content and composition of Nigella sativa L. and Nigella damascena L. Industrial Crops and Products 15(1):59-69.

Datta AK, Saha A, Bhattacharya A, Mandal A, Paul R, Sengupta S (2012). Black cumin (Nigella sativa L.) - A review. Journal of Plant Development Sciences 4(1):1-43.

Ellis RH, Roberts EH (1980). Towards a rational basis for testing seed quality. In: Hebblethwaite PD (Ed). Seed Production. Butterworths, London pp 605-635.
Faravani M, Emami SD, Gholami BA, Faravani A (2013). The effect of salinity on germination, emergence, seed yield and biomass of black cumin. Journal of Agricultural Sciences 58(1):41-49.

Ghaderi FA, Soltani A, Sadeghipour HR (2008). Cardinal temperatures of germination in medicinal pumpkin (Cucurbita pepo convar. pepo var. styriaca), borago (Borago officinalis L.) and black cumin (Nigella sativa L.). Asian Journal of Plant Sciences 7(6):574-578.

Hajar AS, Zidan MA, Al Zahrani HS (1996). Effect of salinity stress on the germination, growth and some physiological activities of black cumin (Nigella sativa L.). Arab Gulf Journal of Scientific Research 14:445-454.

Ibrahim EA (2016). Seed priming to alleviate salinity stress in germinating seeds. Journal of Plant Physiology 192:38-46.

Javadi H, Seghatoleslami MJ, Mosavi SGH (2014). The effect of salinity on seed germination and seedling growth of four medicinal plant species. Iranian Journal of Field Crops Research 12(1):53-64.

Khalid KA (2015). Seed yield, fixed oil, fatty acids and nutrient content of Nigella sativa L. cultivated under salt stress conditions. Journal of Agronomy 14(4):241-246.

Munns R, Tester M (2008) Mechanisms of salinity tolerance. Annual Review of Plant Biology 59:651-681.

Murillo-Amador B, Lopez-Aguilar R, Kaya C, Larrinaga-Mayoral J, Flores-Hernandez A (2002). Comparative effects of $\mathrm{NaCl}$ and polyethylene glycol on germination, emergence and seedling growth of cowpea. Journal of Agronomy and Crop Science 188:235-247.

Piras A, Rosa A, Marongiu B, Porcedda S, Falconieri D, Dessi MA, Ozcelik B, Koca U (2013). Chemical composition and in vitro bioactivity of the volatile and fixed oils of Nigella sativa L. extracted by supercritical carbon dioxide. Industrial Crops and Products 46: 317-323.

Ramadan MF (2007). Nutritional value, functional properties and nutraceutical applications of black cumin (Nigella sativa L.): an overview. International Journal of Food Science and Technology 42:1208-1218.

Tuncturk R, Tuncturk M, Ciftci V (2012). The effects of varying nitrogen doses on yield and some yield components of black cumin (Nigella sativa L.). Advances in Environmental Biology 6(2):855858. 